\title{
Who am I if you can't see me? The "self" of young travellers as driver of eWOM in social media
}

\author{
Maria Ek Styvén and Tim Foster
}

Maria Ek Styvén and Tim Foster are both Associate Professors at the Department of Business Administration, Technology and Social Sciences, Luleå University of Technology, Luleå, Sweden.
Received 5 December 2017 Accepted 13 December 2017

(c) Maria Ek Styvén and

Tim Foster. Published by Emerald Publishing Limited. This article is published under the Creative Commons Attribution

(CC BY 4.0) licence. Anyone may reproduce, distribute, translate and create derivative works of this article (for both commercial and non-commercial purposes), subject to full attribution to the original publication and authors. The full terms of this licence may be seen at http://

creativecommons.org/licences/by/ 4.0/legalcode

This work was supported by the R\&D Fund of the Swedish Tourism \& Hospitality Industry.

\begin{abstract}
Purpose - The purpose of this paper is to analyse factors influencing the propensity to share travel experiences in social media during a trip, across a sample of Millennial and Generation Z consumers in three different countries.

Design/methodology/approach - An online survey was sent to consumers between 16 and 30 years in Sweden, UK and India. Structural equation modelling and multigroup analysis was conducted to compare results between countries and generations.

Findings - Young travellers' need for uniqueness (NFU) and opinion leadership (OL) with regard to travel tends to increase their propensity to share travel experiences in social media during a trip. Reflected appraisal of self is strongly related to NFU and OL and may therefore indirectly influence the propensity to share. Some differences were found between generations and countries.

Research limitations/implications - Future research could consider comparisons between travellers from younger and older generations. The hypotheses formulated in this study could be tested in other countries. Further adaptions or extensions of existing NFU scales to fit in the travel and tourism context are suggested. Practical implications - Millennial and Gen Z consumers will constitute an increasing part of travellers and visitors in the future. Through a better understanding of their behaviour, tourism managers can design strategies to engage them and increase electronic word-of-mouth (eWOM).

Originality/value - This study contributes by addressing the lack of research on "self"-related drivers of eWOM in general social media during the trip, and by providing an international perspective through cross-cultural comparisons.
\end{abstract}

Keywords Social media, Millennials, eWOM, Generation Z, Self, Travel experience

Paper type Research paper

\section{Introduction}

The aim of this paper is to analyse factors influencing the propensity to share travel experiences in social media during a trip, across a sample of Millennial and Gen Z consumers in three different countries. In doing so, this study provides a cross-cultural perspective that is presently lacking when it comes to studies of young travellers' behaviours (Leask et al., 2014). Specifically, the paper addresses "self"-related drivers of electronic word-of-mouth (eWOM) in general social media during a trip, including reflected appraisal of self (RAS), need for uniqueness (NFU), and opinion leadership (OL).

Social media websites and apps such as Facebook have changed the way travellers share and evaluate information, before but also during a trip. When they post and share their travel experiences online, they are often - intentionally or unintentionally - influencing others' perceptions of destinations or brands through eWOM (cf. Goldsmith and Horowitz, 2006). The growing popularity of social media has meant that the thoughts and opinions of other travellers have become more influential as a source of information than the information coming from travel suppliers (Litvin et al., 2008). In addition, recent research suggests that sharing experiences in social media is important for travellers' post-trip experiences and emotions (Kim and Fesenmaier, 2017). 
Hence, there is a need to understand which travellers are posting or sharing content in social media, and why they choose to do this (Bronner and de Hoog, 2011; Kim et al., 2015). However, few studies have looked at who is engaged in eWOM (Kim et al., 2015), and what the motives of users for sharing experiences are (Sukhu and Bilgihan, 2014).

In this context, the digital natives called Millennials are of keen interest to scholarly researchers and practitioners alike, as having grown up with social media can make this group, "a harbinger of how people will behave in the future" (Bolton et al., 2013, p. 246). This is perhaps an even more valid claim regarding the young Generation Z (immediately following the Millennials), which has never really known a world void of the internet, social media, mobile technology, and smart phones (Turner, 2015). As Millennial and Gen Z consumers will constitute an increasing part of travellers and visitors in the future, it is vital for tourism managers to understand them better and design strategies to engage them; otherwise, they risk the spread of negative eWOM (Leask et al., 2014).

While most studies on tourism-related eWOM so far have focussed on travel review and comparison sites such as TripAdvisor (e.g. Bronner and de Hoog, 2011), there is still a lack of research into the drivers of eWOM in social networks such as Facebook or Instagram (Kim et al., 2015), in particular when it comes to sharing during the trip. Previous findings within this area suggest that the more young travellers are using social networks as a window in which they show their own identity, the more likely they are to spread eWOM in social media during a trip (Wallström et al., 2015). Munar and Jacobsen (2014) found that younger tourists, as well as those who said they had or would speak about the trip on social media, identified with self-centred motivations of sharing tourism experiences to a higher degree than others. These notions will be further explored as this study will contribute to the understanding of drivers of eWOM in non-travel-specific social media.

\section{Theoretical background and methodology}

Drawing from the central tenets of identity theory, which is based on symbolic interactionism (Stryker, 1968), we propose that dispositional characteristics reflecting how young people see themselves in relation to their peers will influence their propensity to share travel experiences in social media during a trip. According to identity theory, the self is divided in different identities with different roles, which is defined by the shared meanings of their interactions with others (Stryker, 1968; Taylor et al., 2012). The self is therefore interdependent with social behaviour - such as engaging in eWOM. In the context of social media, the social interactions of individuals could be conceptualised as the propensity to share content with others, which is influenced by the individual's sense of self (Taylor et al., 2012). Specifically, we will test this proposition by addressing the following constructs: RAS (Kim et al., 2015), NFU (Hyun and Park, 2016; Wang et al., 2012), and OL (Eastman et al., 2014; Kim et al., 2015). In addition, travel experience (Teichmann, 2011) is included in order to analyse whether young people who perceive themselves as experienced travellers are more likely to share content online during a trip.

\section{RAS}

The sharing of daily consumption through social media is an important part of modern life and the construction of self-image. Individuals can utilise online social networks to not only post self-relevant information, but interact with others as well, thereby extending their self-identity online (Kim et al., 2015). As Kim et al. (2015) point out, consumers are more likely to engage in eWOM when the product or consumption experience is valued as significant to the self. Such eWOM concerning self-relevant values provides a means of self-presentation, where the virtual world allows consumers to use digital rather than physical references to present some sort of self-image (Kim et al., 2015).

The RAS indicates the importance of how individuals think that others view them (Stets and Burke, 2014). People's desire for positive recognition from others can be part of the motivation for consumers to publicly communicate their consumption experience(s) online (Kim et al., 2015). In a similar vein, Luarn et al. (2016) conclude that that personal (self-relevant) constructs such as 
image building have a positive effect on users' engagement in eWOM on social media. We therefore propose that a higher level of RAS is connected to a stronger propensity to share travel experiences in social media when travelling.

\section{NFU}

In addition to attaching importance to how the self is viewed by others, people are often looking for ways to feel special and differentiate themselves from others in the current era of mass production, mass media, and mass consumption (Song and Lee, 2013). It has been long understood that nearly all individuals have a basic need to feel unique (Snyder and Fromkin, 1980). Today, consumers often select and use products and services to express their individuality and uniqueness (Song and Lee, 2013). Thus, the choice of vacation destinations can be a means of expressing uniqueness, which is then displayed to others through social media.

Consumers' need for self-appraisal has led to an increased need to pursue personal uniqueness in their buying decisions (Hyun and Park, 2016); that is, NFU (Ruvio et al., 2008). It is NFU that drives individuals to pursue dissimilarity relative to others though consumption in order to develop and enhance a distinctive self and social image (Hyun and Park, 2016; Tian et al., 2001). While previous studies on NFU have been primarily based on single-country empirical data, there are calls to test this on a cross-cultural basis (Ruvio et al., 2008). We propose that NFU will be influenced by the RAS, and that it is positively related to the propensity to share travel experiences in social media during a trip.

\section{$O L$}

Self-relevant constructs can also be related to the extent to which consumers tend to be opinion leaders. OL, defined as "an individual's ability to influence other individuals' attitudes or overt behaviour in a desired way in a particular domain" is generally considered an important factor in WOM (Grewal et al., 2000, p. 236). In an online context, eWOM intentions could be differentiated depending on the level of OL held by the consumer (Kim et al., 2015). As social groups (such as Millennials and Gen Z) tend to trust information provided by those similar to them, a greater influence over purchase behaviours occurs. Millennials are inclined to share knowledge that is useful to their "social others", reflecting on how they wish to be seen by their peers (Eastman et al., 2014). Often, people with OL tendencies are more likely than non-opinion leaders to emphasise self-relevant value (Gilly et al., 1998). Research has also found that the social-identity function, which mediates the self and other interactions, is an antecedent to OL (Grewal et al., 2000). This would suggest that RAS can be connected to a stronger tendency to OL.

From the literature review above, the following hypotheses emerge:

H1a. RAS is positively related to the propensity to share travel experiences in social media during a trip.

H1b. RAS is positively related to NFU.

H1c. RAS is positively related to OL.

H2. NFU is positively related to the propensity to share travel experiences in social media during a trip.

H3. OL is positively related to the propensity to share travel experiences in social media during a trip.

\section{Travel experience}

In addition to the self-relevant constructs highlighted in the previous sections, we propose that travel experience potentially influences the propensity to share travel experiences (i.e. content) in social media during a trip. Prior experience is one of the most commonly investigated factors influencing the decision-making process in tourism, and can be conceptualised as either previous visits to a destination or previous travel experience in general (Teichmann, 2011). In this study, we investigate "general", self-evaluated travel experience; that is, not related to a specific destination. 
Further, the more experience someone has, the higher their knowledge of that experience. Research suggests that in an online context, opinion leaders have significantly higher levels of self-perceived knowledge compared to non-leaders; that is, the subjective amount of information consumers think they know about a product or service (Eastman et al., 2014; Lyons and Henderson, 2005). An opinion leader should possess the ability to judge a product (or service) accurately, as a knowledgeable consumer should know which criteria to use in such judgements (Bettman and Sujan, 1987). We argue that it is likely that the more travel experience a consumer has, the higher his/her self-perceived knowledge, and the more likely he/she will view him-/herself as an opinion leader when it comes to travel. Hence, we hypothesise:

H4a. The level of previous travel experience is positively related to the propensity to share travel experiences in social media during a trip.

H4b. The level of previous travel experience is positively related to OL.

Figure 1 depicts the research model with the hypothesised relationships to be tested.

\section{Research method}

Data were collected through an online survey to empirically test the proposed relationships. A questionnaire was constructed based on items used in previous research. NFU was measured with four items from Wang et al. (2012) and Hyun and Park (2016). As the NFU scales were originally used for products other than travel, not all of the items were relevant or easily adaptable to our context, and we therefore combined items from these two sources. Further, a three-item scale from Kim et al. (2015) was used for RAS. For OL, we adopted a three-item scale from Eastman et al. (2014), which is based on Flynn et al. (1996). The measure of travel experience was based on Teichmann (2011), with the addition of a fourth item which differentiates between experience of travelling in the home country vs travelling to other countries. All items for the independent constructs were measured using a seven-point Likert-type scale, with anchors ranging from "Strongly disagree" (1) to "Strongly agree" (7). All questions were formulated to focus on leisure travel; that is, "To what extent do you agree with the following statements about holiday trips?"

The dependent construct, labelled "Propensity to Share" in the research model, was conceptualised as the propensity to share travel experiences in general social media during a vacation trip. This was measured by six items covering different forms of actively sharing content on social media during travel: uploading photos, posting video clips, writing status updates, writing comments, "checking in", and tagging (Wallström et al., 2015). A five-point scale ranging from "Never" (0) to "Always" (4) was used for these items. Using different endpoints for the dependent and independent constructs, as well as using easily understandable questions, can mitigate bias caused by common method variance (Podsakoff et al., 2003). In addition to the measures described above, the instrument included questions covering common demographics such as gender, age, and main occupation.

Figure 1 Research model

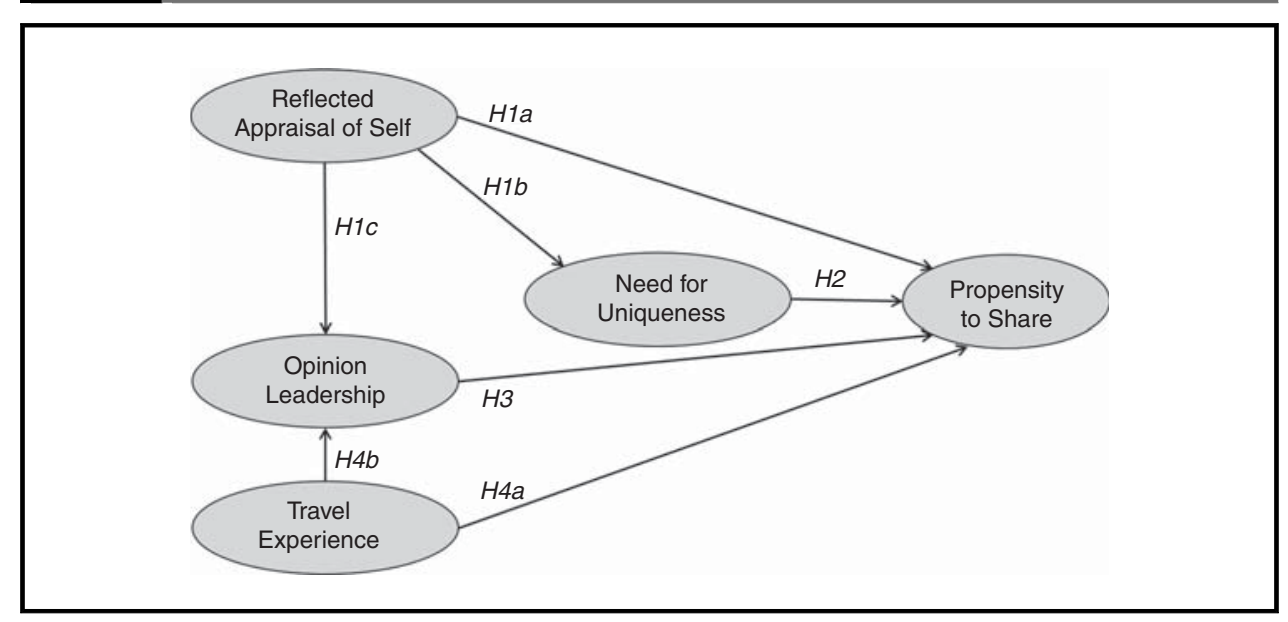


The questionnaire was constructed in the online survey tool Qualtrics and distributed to web panels of consumers between 16 and 30 years in Sweden, UK and India. These countries were chosen in collaboration with an expert group of six tourism managers in Sweden, and were selected for the following reasons: first, the domestic market is crucial as Swedish tourists account for 60 per cent of the total tourism consumption in Sweden (Tillväxtverket, 2017). Second, the UK is the fourth largest source of international tourists in Sweden with a rapidly growing number of visitors (Tillväxtverket, 2017). Third, India represents a huge potential as a target market considering its large population, of which many are young, well educated, and connected. The number of Indian tourists in Sweden, while still rather low, increased by 266 per cent between 2009 and 2015 (Tillväxtverket, 2016). Studying these seemingly different countries addresses the aim of providing a cross-cultural perspective and investigates the extent to which behavioural patterns are uniform among young consumers, which has been suggested (Leask et al., 2014).

In total, we received 922 responses; of which 309 came from Sweden, 307 from the UK, and 306 from India. The sample was evenly distributed in terms of gender, with 48.9 per cent male respondents and 49.2 per cent female ( 1.8 per cent chose the option "other/do not want to disclose"). The mean age of the total sample was $23.1(\mathrm{SD}=4.16)$ and the median 23 years. Almost half of the respondents (47.8 per cent) were working, while 43.1 per cent were students and 6.7 per cent unemployed. There were no differences between the three countries with regard to gender or age, but the Swedish sample had a slightly higher ratio of students compared to UK and India.

Data were controlled, and descriptives obtained, using the software SPSS 23. Then, structural equation modelling (SEM) with maximum likelihood estimation was applied, using SPSS Amos 23 to estimate the research model and test the hypotheses. SEM techniques provide a simultaneous test of relationships among multiple independent and dependent constructs (Gefen et al., 2000). While the SEM technique by itself does not prove causality, it is useful for testing functional relationships among constructs (Bagozzi and Yi, 2012).

\section{Measurement validation}

Assessment of normality showed that the distribution was normal for all variables, with skewness and kurtosis values within recommended levels (Hair et al., 2007). One respondent (UK) was removed due to missing values in the dependent variable; otherwise, all responses were complete.

Before testing the research model, we ran a confirmatory factor analysis (CFA) to evaluate and refine the scales (cf. Gerbing and Anderson, 1988). Based on assessments of model fit indices, factor loadings, standardized residuals, and modification indices (all of which can indicate validity problems), three items were dropped (TE1, NFU1, and NFU2). In all three cases, dropping the item resulted in an increase of Cronbach's $\alpha$. It should be noted that the excluded TE item was reverse-scaled, which tends to have a negative effect on measure consistency (Ping, 2004). Both of the items that were dropped from the NFU scale were from Wang et al. (2012) while the remaining two items originated from Hyun and Park (2016). Thus, it seems that the two different NFU scales could not be combined into one construct.

The final measurement model had a $\chi^{2} /$ df of $4.178(p<0.001), \mathrm{CFI}=0.969$, and RMSEA $=0.059$. According to Hair et al.'s (2010, p. 672) guidelines for fit indices, the model exceeds the criteria for goodness-of-fit for larger samples $(n>250)$ with a medium number of observed variables (12-30). This suggests that the model represents an appropriate picture of the data. Further, discriminant and convergent validity among constructs was assessed by examining whether: all standardized factor loadings were significant and higher than 0.50; the squared correlations between each pair of constructs were less than the average variance extracted (AVE) for each construct; and the AVE for each construct was higher than 0.50 (Hair et al., 2010). These criteria were met in most instances (see Table I); however, RAS was strongly correlated with NFU and OL. Therefore, we tested the model with the value of the relationship between RAS and NFU set to 1.0. This resulted in a deterioration in model fit $\left(\chi^{2} / \mathrm{df}=6.811, \mathrm{CFI}=0.943\right.$, and RMSEA $=0.079$ ). Similarly, fixing the path between RAS and OL to 1.0 provided worse fit 
Table I Correlation matrix (CFA results)

\begin{tabular}{lccccccc} 
Construct & No. of items & Cronbach's $\alpha$ & PTS & RAS & NFU & OL & TE \\
\hline Propensity to share (PTS) & 6 & 0.92 & 0.657 & & & & \\
Reflected appraisal of self (RAS) & 3 & 0.84 & 0.441 & 0.644 & & & \\
Need for uniqueness (NFU) & 2 & 0.91 & 0.420 & 0.839 & 0.842 & & \\
Opinion leadership (OL) & 4 & 0.92 & 0.403 & 0.671 & 0.546 & 0.744 & \\
Travel experience (TE) & 3 & 0.81 & 0.252 & 0.388 & 0.321 & 0.602 & 0.593
\end{tabular}

Note: Diagonal values in italics represent AVE

$\left(\chi^{2} / \mathrm{df}=5.654, \mathrm{CFI}=0.954\right.$, and RMSEA $\left.=0.071\right)$, suggesting that these constructs were closely related, but separate (Hair et al., 2010). Considering these results and the theoretical foundation for the constructs, we decided to retain all items according to the tested measurement model.

\section{Findings}

\section{Model results and hypothesis tests}

After validating the measures, the path model in Amos was estimated with maximum likelihood estimation (recommended by, e.g. lacobucci, 2010) to test the hypotheses. When specifying the model, exogenous variables should be allowed to correlate freely, unless it can be reasonably assumed that they are completely uncorrelated (cf. Arbuckle, 2013). As the CFA suggested that RAS and travel experience were at least moderately correlated, we included a non-directional correlation between these two constructs. Running the model with this correlation and the hypothesised paths resulted in satisfactory fit: $\chi^{2} / \mathrm{df}=4.116(p<0.001), \mathrm{CFI}=0.969$, and $\mathrm{RMSEA}=0.058$. Figure 2 provides an overall view of the tested model.

Results show that the model could explain 83.4 per cent of the variance in NFU, 78.2 per cent of the variance in OL, and 47.8 per cent of the variance in the propensity to use social media for sharing travel experiences. $\mathrm{H} 1 \mathrm{a}$, which assumes a direct positive relationship between RAS and Propensity to Share was rejected. However, in line with $\mathrm{H} 1 \mathrm{~b}$ and $\mathrm{H} 1 \mathrm{c}$, RAS was found to be strongly related to NFU and OL, respectively. In turn, NFU and OL showed moderately strong relationships to Propensity to Share, as expected in $\mathrm{H}_{2}$ and $\mathrm{H} 3$. Similarly, model results show that Travel Experience had no influence on Propensity to Share, rejecting $\mathrm{H} 4 \mathrm{a}$, but it is related to OL, in accordance with H4b. In addition to the hypothesised relationships, we found that RAS and Travel Experience were strongly correlated. Table II summarises the results of the hypothesis tests.

Figure 2 Structural model results

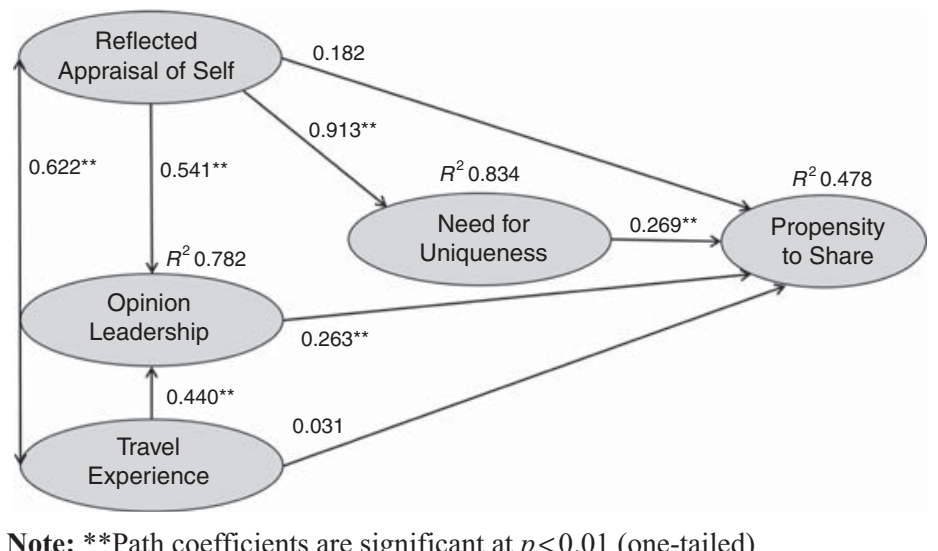

Note: ${ }^{*}$ Path coefficients are significant at $p<0.01$ (one-tailed) 
Table II Results of hypothesis testing

\begin{tabular}{lcrl} 
Hypotheses & Path coefficient & $t$ & Supported? \\
\hline H1a RAS $\rightarrow$ PTS & $0.182^{\text {ns }}$ & 1.494 & No \\
H1b RAS $\rightarrow$ NFU & $0.913^{\star *}$ & 31.839 & Yes \\
H1c RAS $\rightarrow$ OL & $0.541^{\star \star}$ & 16.981 & Yes \\
H2 NFU $\rightarrow$ PTS & $0.269^{\star \star}$ & 2.712 & Yes \\
H3 OL $\rightarrow$ PTS & $0.263^{\star *}$ & 3.525 & Yes \\
H4a TE $\rightarrow$ PTS & $0.031^{\text {ns }}$ & 0.597 & No \\
H4b TE $\rightarrow$ OL & $0.440^{\star *}$ & 13.376 & Yes \\
RAS $\leftrightarrow$ TE & $0.622^{\star *}$ & 13.703 & Not hypothesised
\end{tabular}

Notes: ${ }^{\star} p<0.05 ;{ }^{* \star} p<0.01$ (one-tailed); ${ }^{\text {ns }} p>0.05$

\section{Multigroup analysis - measurement invariance}

In order to test for possible differences between countries and between generations, we performed multigroup analysis in Amos. Each estimated path was constrained to be equal in both groups. A significant difference in $\chi^{2}$ between the unconstrained and the constrained model indicates that the strength of the path coefficient in fact differs between groups (Hair et al., 2010). Before proceeding with the multigroup analysis, we tested the measurement model for invariance across groups (Byrne, 2004). Results indicated that full metric invariance was achieved for three of the five constructs, while Propensity to Share and Travel Experience were partially invariant (i.e. at least two indicators per construct were invariant). More specifically, four to five of the six PTS indicators, and two of the three TE indicators, were invariant between groups. Following the recommendations of Hair et al. (2010), the model was found acceptable for making comparisons of relationships between constructs.

\section{Comparison between countries}

First, we ran the model with respondents from each country as a separate group. As shown in Table III, model fit was satisfactory in all three groups. As $\chi^{2}$ increases with large sample sizes (Hair et al., 2010), the $\chi^{2} /$ df is lower in these sub-samples compared to when the model was run with all 921 respondents. Across the groups, the model explained between 35.1 and 46.9 per cent of the variance in Propensity to Share, 74.5 - 84.3 per cent of NFU, and 65.4 - 82.8 per cent of OL.

Table III Multigroup analysis - countries

\begin{tabular}{|c|c|c|c|c|c|}
\hline \multirow[t]{2}{*}{ Path } & \multicolumn{3}{|c|}{ Standardized path estimates (Unconstrained model) } & \multicolumn{2}{|c|}{ Significance of difference between path estimates under constraint } \\
\hline & Sweden $(n=309)$ & $U K(n=306)$ & India $(n=306)$ & Change in $\chi^{2}$ & $p$ \\
\hline H1a RAS $\rightarrow$ PTS & $0.070^{\text {ns }}$ & $0.150^{\mathrm{ns}}$ & $0.175^{\mathrm{ns}}$ & 0.235 & 0.889 \\
\hline $\mathrm{H} 1 \mathrm{~b}$ RAS $\rightarrow \mathrm{NFU}$ & $0.910^{\star \star}$ & $0.918^{\star \star}$ & $0.863^{\star \star}$ & 9.179 & 0.010 \\
\hline $\mathrm{H} 1 \mathrm{c} \mathrm{RAS} \rightarrow \mathrm{OL}$ & $0.550^{\star *}$ & $0.456^{\star *}$ & $0.334^{\star \star}$ & 16.159 & 0.001 \\
\hline $\mathrm{H} 2 \mathrm{NFU} \rightarrow \mathrm{PTS}$ & $0.302^{*}$ & $0.393^{*}$ & $0.129^{\text {ns }}$ & 1.002 & 0.606 \\
\hline $\mathrm{H} 3 \mathrm{OL} \rightarrow \mathrm{PTS}$ & $0.316^{\star \star}$ & $0.001^{\mathrm{ns}}$ & $0.280^{\star}$ & 2.721 & 0.257 \\
\hline TE $\rightarrow$ PTS & $-0.046^{\mathrm{ns}}$ & $0.194^{*}$ & $0.073^{\text {ns }}$ & 3.454 & 0.178 \\
\hline $\mathrm{TE} \rightarrow \mathrm{OL}$ & $0.418^{\star \star}$ & $0.522^{\star \star}$ & $0.616^{\star \star}$ & 2.160 & 0.340 \\
\hline $\mathrm{RAS} \leftrightarrow \mathrm{TE}$ & $0.386^{\star \star}$ & $0.731^{\star \star}$ & $0.663^{\star \star}$ & 11.997 & 0.002 \\
\hline \multicolumn{6}{|l|}{ Model fit indexes } \\
\hline$\chi^{2} / \mathrm{df}(p)$ & $2.630(0.000)$ & $2.726(0.000)$ & $2.218(0.000)$ & & \\
\hline CFI & 0.944 & 0.953 & 0.954 & & \\
\hline RMSEA & 0.073 & 0.075 & 0.063 & & \\
\hline \multicolumn{6}{|c|}{ Squared multiple correlations } \\
\hline Propensity to share & 0.362 & 0.469 & 0.351 & & \\
\hline Need for uniqueness & 0.827 & 0.843 & 0.745 & & \\
\hline Opinion leadership & 0.654 & 0.828 & 0.764 & & \\
\hline \multicolumn{6}{|c|}{ Notes: ${ }^{\star} p<0.05 ;{ }^{* \star} p<0.01$ (one-tailed); ${ }^{n s} p>0.05$} \\
\hline
\end{tabular}


Consistent with the results in the total sample, the multigroup comparison showed no significant relationship between RAS and Propensity to Share in any of the three countries. Similarly, the path between Travel Experience and Propensity to Share was non-significant in the Swedish and Indian samples, while it was significant $(p=0.043)$ in the British group. However, this difference between countries could not be statistically verified. The relation between Travel Experience and OL seems to be consistent and fairly strong across the samples. NFU and Propensity to Share had a moderately strong correlation in the Swedish and British samples but was non-significant for India, while the path between OL and Propensity to Share had a virtually non-existing relationship in the British sample. None of these differences were statistically significant in terms of change in $\chi^{2}$.

Looking at the paths for which the analysis actually showed significant differences, it seems that the influence of RAS differs between the samples. While this construct was very strongly correlated to NFU in all three countries, the relationship was somewhat weaker in the Indian sample compared to the other two. Similarly, the path coefficient between RAS and OL was lower for the Indian respondents, and higher for the Swedes. At the same time, RAS had a very high correlation with Travel Experience in the UK and Indian samples, but comparatively lower in the Swedish sample.

\section{Comparison between generations}

Next, in order to compare the model between Millennials and Generation Z, we first needed to establish at which age to split the sample. While there is no overall agreement on the exact boundaries of each generation, many authors refer to Generation $Z$ as those born between the mid-1990s and about 2010 (e.g. Turner, 2015). Hence, the Millennials are by definition born before the middle of the 1990s. In our sample, 41.5 per cent $(n=382)$ of the respondents were between 16 and 21 years and were therefore categorised as belonging to Generation Z, while the remaining 539 respondents consequently were categorised as Millennials.

Fit indexes showed a satisfactory fit between the model and the data (see Table IV). The model explained between 40.0 to 51.5 per cent of the variance in Propensity to Share, 74.0 - 89.1 per cent of $\mathrm{NFU}$, and 66.3 - 84.6 per cent of OL. All of the higher $R^{2}$ values pertained to the Millennials sub-sample.

In the same way as in the total sample, neither RAS nor Travel Experience was significantly correlated to Propensity to Share in any of the two groups. The strength of the paths from RAS to

\section{Table IV Multigroup analysis - generations}

Path

Standardized path estimntes
Generation $Z(n=382)$

\begin{tabular}{l}
\hline H1a RAS $\rightarrow$ PTS \\
H1b RAS $\rightarrow$ NFU \\
H1c RAS $\rightarrow$ OL \\
H2 NFU $\rightarrow$ PTS \\
H3 OL $\rightarrow$ PTS \\
H4a TE $\rightarrow$ PTS \\
H4b TE $\rightarrow$ OL
\end{tabular}

\section{$0.103^{\text {ns }}$}

$0.861^{* *}$

$0.572^{\star \star}$

$0.372^{* \star}$

$0.233^{* *}$

$-0.026^{\text {ns }}$

$0.358^{\star \star}$

$0.507^{\star *}$

\subsection{8}

0.968

0.053

Model fit indexes (Unconstrained)

$\chi^{2} / \mathrm{df}(p)$

RMSEA

Squared multiple correlations

Propensity to share

Need for uniqueness

Opinion leadership

$\begin{array}{ll}0.400 & 0.515 \\ 0.740 & 0.891 \\ 0.663 & 0.846\end{array}$

(unconstrained model) Millennials $(n=539)$
Significance of difference between path estimates under constraint Change in $\chi^{2}$

$\begin{array}{ll}0.677 & 0.411 \\ 0.665 & 0.415 \\ 0.818 & 0.366 \\ 0.723 & 0.395 \\ 0.154 & 0.694 \\ 1.060 & 0.303 \\ 7.766 & 0.005 \\ 5.178 & 0.023\end{array}$

$p$

0.411

415

0.694

.005

.023

Notes: ${ }^{\star} p<0.05$; ${ }^{* \star} p<0.01$ (one-tailed); ${ }^{\text {ns }} p>0.05$
$0.292^{\text {ns }}$
$0.944^{\star *}$
$0.508^{\star \star}$
$0.136^{\text {ns }}$
$0.257^{\star \star}$
$0.082^{\mathrm{ns}}$
$0.494^{\star \star}$
$0.684^{\star *}$
3.638
0.961
0.070
0.891
.846 
$\mathrm{NFU}$ and OL, respectively, was equally strong in both sub-samples. The relationship between $\mathrm{OL}$ and Propensity to Share was also very similar between the groups. In contrast, the path from NFU to Propensity to Share, which was moderately strong in the Generation Z sample, was non-significant among the Millennials. This difference was however not supported by the $\chi^{2}$ statistic.

The level of travel experience seems to have a somewhat different influence between the two generations. The significant changes in $\chi^{2}$ when constraining the path from Travel Experience to $\mathrm{OL}$, and between Travel Experience and RAS, suggests that these relationships are stronger for the (relatively older) Millennials than for the young Gen Z travellers.

\section{Discussion and theoretical implications}

The strong relationship between RAS and NFU implies that for Millennial and Generation Z consumers who attach high importance to how others view them, it is also very important that the destinations they travel to express that they are different and unique. That is, the selection of destinations they visit becomes a means for creating a positive impression among peers. As the RAS is also connected to OL, these consumers' concern with how they are perceived in the eyes of others seems to increase their tendencies in trying to influence others' travel choices. These findings add to the understanding of self-relevant constructs in the context of travel (e.g. Kim et al., 2015).

Though the RAS is not significantly related to the propensity to share travel experiences in social media during a trip, it seems that it could at least have an indirect effect through NFU and OL. NFU is positively related to the propensity to share, suggesting that the more important it is for these young travellers to feel unique in their travel experiences, the more likely they will share those experiences in social media. This way, eWOM becomes a means for expressing their individuality and uniqueness (cf. Song and Lee, 2013). OL is also positively related to the propensity to share, suggesting that Millennials and Gen Z consumers, who like to influence others, are also more likely to share their travel experiences online during the trip, thus actively spreading $\mathrm{eWOM}$ about the places they visit. This confirms previous studies on OL (e.g. Grewal et al., 2000) also in the context of young travellers.

Finally, there was no connection between previous, self-evaluated travel experience and the propensity to share travel experiences in social media during a trip, but the relationship between travel experience and $\mathrm{OL}$ was fairly strong. This suggests that the more travel experience consumers gain, the higher their self-perceived knowledge, and the more likely they consider themselves as opinion leaders to be relied upon for their expertise when it comes to travel. However, the gained experience does not mean they are always willing to connect to, upload or share their on-going travel experiences to the various social media they use. While the self-perceived knowledge is implicit in this study, the link between travel experience and OL confirms and extends previous research (Eastman et al., 2014; Lyons and Henderson, 2005).

The multi-group comparisons between the two generations (Millennials and Generation Z) and three different countries (Sweden, UK, and India) yielded few significant differences. It appears that the RAS has a slightly different influence in the sampled countries - for example, it is more strongly connected to $\mathrm{OL}$ in Sweden than in India. Travel experience seems to play a somewhat more important role for Millennials than for Gen Z; perhaps simply because they are older and have travelled more. These results suggest that young people today have more in common across national borders and between their generations than there are differences between them.

The overall aim of this study was to analyse factors influencing the propensity to share travel experiences in general social media during a trip, across a sample of Millennial and Gen Z consumers in three different countries. In doing so, this paper has responded to calls for more research on examining consumer motives for eWOM behaviour (Kim et al., 2015; Wang et al., 2012), the role of technology for Millennials and Gen Z generations (Eastman et al., 2014), and the need to continually understand NFU, especially among younger generations (Song and Lee, 2013). The study also contributes to research by starting to fill the gap that has existed on cross-cultural perspectives with regard to NFU (Ruvio et al., 2008) and Millennials' travel behaviours (Leask et al., 2014). 


\section{Limitations and suggestions for future research}

The findings discussed in the previous sections should be considered in light of some limitations. With regard to measurement, we dropped two items from NFU, suggesting that the two different NFU scales from which the items were chosen could not be combined into one construct. On the other hand, even with only two items, the NFU construct showed high levels of reliability and validity. Future research could make further adaptions or extensions of existing NFU scales to fit in the travel and tourism context.

Moreover, the CFA showed that the RAS construct was strongly correlated with NFU and OL, which could put the discriminant validity into question. Researchers could explore and test whether the RAS and NFU constructs might be two separate but closely related dimensions of a second-order construct reflecting the importance to feel unique in the eyes of others. While RAS and travel experience did not have any significant correlation with the propensity to share, it is possible that these constructs could fill another function, as mediators or moderators in a revised model. It could also be worthwhile to include subjective (self-perceived) knowledge as an outcome of travel experience. Numerous other self-relevant constructs also remain to be tested in this specific context, for example expressiveness or image building.

Furthermore, this paper has limitations related to looking at Millennial and Gen Z samples in just three countries. Future research should consider comparisons between these generations and those from older generations who are either retired/soon retiring (Baby Boomers) or are at the peak of their careers with higher earning power (Generation X). It is also recommended that researchers test the hypotheses formulated in this study in other countries to see if similar results occur. All of this must be tempered by the fact that no one controls social media and where it is headed in the future. "Moore's Law", or the doubling of computing power every 18 months, will dictate that what we know about how information is shared and sought will continually change as information technology evolves.

\section{Practical implications}

The results above provide some important implications for tourism managers and entrepreneurs. A better understanding of Millennial and Gen Z consumers is essential as they will constitute an increasing part of travellers and visitors in the future. As they continue to move into adulthood and develop within their careers, ultimately earning more disposable income, they will carefully consider where they spend that money when it comes to travelling. Through knowledge about aspects that drive these consumers to post and share content online, tourism managers can design future strategies to engage them and increase the positive eWOM about destinations and brands.

The most important implication is that customers and guests have become the ones ultimately promoting travel and tourism brand(s). Specifically, tourist destination managers and entrepreneurs should consider the following as they approach the future tourists:

- The image of the brand, be it a destination, activity, hotel or restaurant, will be earned through the conversations these generations will continue to have about what they experience.

- These generations will continue to connect their travel experience brand to their personal brand, as what they do and spend money on is a reflection of their appraisal of self, i.e. their concern with what others think of them.

- The uniqueness of their travel experience will make them not only feel more unique as individuals, but the more unique they feel based on their experiences, the more likely they are willing to share their experience on social media.

- Because of their propensity to share content online, Millennials and Gen Z are taking over promotion, as they are using each other to share and seek the information they need to make travel experience decisions.

- This implies that the product is the most important for marketers - learn to exceed customers' expectations while they are visiting/using your brand. Again, the more unique the experience, the more unique they feel; thus the more likely they will talk about it. 
- These "conversations" will continue to be shared through a variety of existing and yet-to-be invented social media, where these generations go to seek and share all forms of communication about their daily personal and professional lives.

- Which country these young people come from and/or which generation they belong to (Millennial vs Gen Z) may not matter as much. These people have more in common across national borders and between their generations than there are differences between them. This is a good example of globalisation in today's and tomorrow's markets.

- The travel experiences of these generations will continue to be shaped and shared by opinion leaders as "experts" on the brand experience. Many opinion seekers will use these shared experiences to decide where to spend their hard-earned disposable income.

- Like catering to a food critic, trying to find and influence these opinion leaders, providing them with exceptional and unique experiences, should be the primary focus of the travel experience provider in the future. Simply put, give a Millennial opinion leader a "Bucket List" experience, and 100 will follow.

\section{Originality/value}

This study contributes to the body of knowledge by addressing the lack of research on "self"-related drivers of eWOM in general social media during the trip. It also provides an international perspective by making cross-cultural comparisons between young consumers in three different countries. The focus on Millennial and Gen Z travellers is also of value, as they will continue to want to feel more special through the uniqueness of their respective travel experiences. These up-and-coming consumers represent a future for travel destination managers and entrepreneurs where the communication of the travel experience brand is in the hands of the people paying for those experiences. Thus, the product remains in the marketer's control, while the promotion will be more and more in the hands of the consumer. Welcome to travel and tourism in the twenty-first century.

\section{References}

Arbuckle, J.L. (2013), IBM SPSS Amos 22 User's Guide, IBM/Amos Development Corporation.

Bagozzi, R.P. and Yi, Y. (2012), "Specification, evaluation, and interpretation of structural equation models", Journal of the Academy of Marketing Science, Vol. 40 No. 1, pp. 8-34.

Bettman, J.R. and Sujan, M. (1987), "Effects of framing on evaluation of comparable and noncomparable alternatives by expert and novice consumers", Journal of Consumer Research, Vol. 14 No. 2, pp. 141-54.

Bolton, R.N., Parasuraman, A., Hoefnagels, A., Migchels, N., Kabadayi, S., Gruber, T., Komarova Loureiro, Y. and Solnet, D. (2013), "Understanding Generation $Y$ and their use of social media: a review and research agenda", Journal of Service Management, Vol. 24 No. 3, pp. 245-67.

Bronner, F. and de Hoog, R. (2011), "Vacationers and eWOM: who posts, and why, where, and what?", Journal of Travel Research, Vol. 50 No. 1, pp. 15-26.

Byrne, B.M. (2004), "Testing for multigroup invariance using AMOS graphics: a road less traveled”, Structural Equation Modeling: A Multidisciplinary Journal, Vol. 11 No. 2, pp. 272-300.

Eastman, J.K., Iyer, R., Liao-Troth, S., Williams, D.F. and Griffin, M. (2014), "The role of involvement on millennials' mobile technology behaviors: the moderating impact of status consumption, innovation, and opinion leadership", Journal of Marketing Theory and Practice, Vol. 22 No. 4, pp. 455-70.

Flynn, L., Goldsmith, R. and Eastman, J. (1996), “Opinion leaders and opinion seekers: two new measurement scales", Journal of the Academy of Marketing Science, Vol. 24 No. 2, pp. 137-47.

Gefen, D., Straub, D. and Boudreau, M.-C. (2000), "Structural equation modeling and regression: guidelines for research practice", Communications of the Association for Information systems, Vol. 4, pp. 1-77.

Gerbing, D.W. and Anderson, J.C. (1988), "An updated paradigm for scale development incorporating unidimensionality and its assessment”, Journal of Marketing Research, Vol. 25 No. 2, pp. 186-92. 
Gilly, M.C., Graham, J.L., Wolfinbarger, M.F. and Yale, L.J. (1998), "A dyadic study of interpersonal information search", Journal of the Academy of Marketing Science, Vol. 26 No. 2, pp. 83-100.

Goldsmith, R.E. and Horowitz, D. (2006), "Measuring motivations for online opinion seeking", Journal of interactive advertising, Vol. 6 No. 2, pp. 2-14.

Grewal, R., Mehta, R. and Kardes, F.R. (2000), "The role of the social-identity function of attitudes in consumer innovativeness and opinion leadership”, Journal of Economic Psychology, Vol. 21 No. 3, pp. 233-52.

Hair, J.F., Black, W.C., Babin, B.J. and Anderson, R.E. (2010), Multivariate Data Analysis: A Global Perspective, Pearson Education, Upper Saddle River, NJ.

Hair, J.F., Money, A.H., Samouel, P. and Page, M. (2007), Research Methods for Business, John Wiley \& Sons Ltd, West Sussex.

Hyun, S.S. and Park, S.H. (2016), "The Antecedents and consequences of travelers' need for uniqueness: an empirical study of restaurant experiences", Asia Pacific Journal of Tourism Research, Vol. 21 No. 6, pp. 596-623.

lacobucci, D. (2010), "Structural equations modeling: fit indices, sample size, and advanced topics", Journal of Consumer Psychology, Vol. 20 No. 1, pp. 90-8.

Kim, D., Jang, S. and Adler, H. (2015), "What drives café customers to spread eWOM?: Examining self-relevant value, quality value, and opinion leadership", International Journal of Contemporary Hospitality Management, Vol. 27 No. 2, pp. 261-82.

Kim, J.J. and Fesenmaier, D.R. (2017), "Sharing tourism experiences: the post-trip experience", Journal of Travel Research, Vol. 56 No. 1, pp. 28-40.

Leask, A., Fyall, A. and Barron, P. (2014), "Generation Y: an agenda for future visitor attraction research", International Journal of Tourism Research, Vol. 16 No. 5, pp. 462-71.

Litvin, S.W., Goldsmith, R.E. and Pan, B. (2008), "Electronic word-of-mouth in hospitality and tourism management", Tourism Management, Vol. 29 No. 3, pp. 458-68.

Luarn, P., Huang, P., Chiu, Y.-P. and Chen, I.-J. (2016), "Motivations to engage in word-of-mouth behavior on social network sites", Information Development, Vol. 32 No. 4, pp. 1253-65.

Lyons, B. and Henderson, K. (2005), "Opinion leadership in a computer-mediated environment", Journal of Consumer Behaviour, Vol. 4 No. 5, pp. 319-29.

Munar, A.M. and Jacobsen, J.K.S. (2014), "Motivations for sharing tourism experiences through social media", Tourism Management, Vol. 43, August, pp. 46-54.

Ping, R.A. Jr (2004), "On assuring valid measures for theoretical models using survey data", Journal of Business Research, Vol. 57 No. 2, pp. 125-41.

Podsakoff, P.M., MacKenzie, S.B., Lee, J.-Y. and Podsakoff, N.P. (2003), "Common method biases in behavioral research: a critical review of the literature and recommended remedies", Journal of Applied Psychology, Vol. 88 No. 5, pp. 879-903.

Ruvio, A., Shoham, A. and Makovec Brenčič, M. (2008), "Consumers' need for uniqueness: short-form scale development and cross-cultural validation”, International Marketing Review, Vol. 25 No. 1, pp. 33-53.

Snyder, C.R. and Fromkin, H.L. (1980), Uniqueness: The human Pursuit of Difference, Plenum Press, New York, NY.

Song, D. and Lee, J. (2013), "Balancing 'We' and 'l': self-construal and an alternative approach to seeking uniqueness", Journal of Consumer Behaviour, Vol. 12 No. 6, pp. 506-16.

Stets, J.E. and Burke, P.J. (2014), "Self-esteem and identities", Sociological Perspectives, Vol. 57 No. 4, pp. 409-33.

Stryker, S. (1968), "Identity Salience and role performance: the relevance of symbolic interaction theory for family research", Journal of Marriage and Family, Vol. 30 No. 4, pp. 558-64.

Sukhu, A. and Bilgihan, A. (2014), "Why travellers share information online: a model of trust, innovativeness and loyalty in generation $Y$ travellers", International Journal of Services, Economics and Management, Vol. 6 No. 2, pp. 115-31.

Taylor, D.G., Strutton, D. and Thompson, K. (2012), "Self-enhancement as a motivation for sharing online advertising", Journal of Interactive Advertising, Vol. 12 No. 2, pp. 13-28. 
Teichmann, K. (2011), "Expertise, experience and self-confidence in consumers' travel information search", International Journal of Culture, Tourism and Hospitality Research, Vol. 5 No. 2, pp. 184-94.

Tian, K.T., Bearden, W.O. and Hunter, G.L. (2001), "Consumers' need for uniqueness: scale development and validation", Journal of Consumer Research, Vol. 28 No. 1, pp. 50-66.

Tillväxtverket (2016), "Fakta om svensk turism 2015 (facts about Swedish tourism 2015)", Tillväxtverket (The Swedish Agency for Economic and Regional Growth), Stockholm.

Tillväxtverket (2017), "Fakta om svensk turism 2016 (facts about Swedish tourism 2016)", Tillväxtverket (The Swedish Agency for Economic and Regional Growth), Stockholm.

Turner, A. (2015), "Generation Z: technology and social interest", Journal of Individual Psychology, Vol. 71 No. 2, pp. 103-13.

Wallström, Å., Engström, A., Ek Styvén, M. and Foster, T. (2015), "Postcards from Digitalville: e-generation tourists' use of social media", in Buhalis, D. and Mariani, M.M. (Eds), 5th International Conference on Tourism Management and Tourism Related Issues, EIASM, Brussels, pp. 1-10.

Wang, X., Yu, C. and Wei, Y. (2012), "Social media peer communication and impacts on purchase intentions: a consumer socialization framework", Journal of Interactive Marketing, Vol. 26 No. 4, pp. 198-208.

\section{Corresponding author}

Maria Ek Styvén can be contacted at: maria.styven@|tu.se

For instructions on how to order reprints of this article, please visit our website: 